\title{
28 Research Square \\ Repair of Aluminum 6061 Plate by Additive Friction Stir Deposition
}

\section{Louis Peter Martin ( $\sim$ LPMGIS@RIT.EDU)}

Rochester Institute of Technology https://orcid.org/0000-0002-1087-4698

\author{
Allen Luccitti \\ Rochester Institute of Technology \\ Mark Walluk \\ Rochester Institute of Technology
}

\section{Research Article}

Keywords: Additive Friction Stir Deposition, AFSD, 6061-T6, Repair

Posted Date: April 26th, 2021

DOI: https://doi.org/10.21203/rs.3.rs-452633/v1

License: (1) This work is licensed under a Creative Commons Attribution 4.0 International License. Read Full License

Version of Record: A version of this preprint was published at The International Journal of Advanced Manufacturing Technology on September 8th, 2021. See the published version at https://doi.org/10.1007/s00170-021-07953-z. 


\section{Abstract}

The deposition of new alloy to replace a worn or damaged surface layer is a common strategy for repairing or remanufacturing structural components. For high-performance aluminum alloys common in the automotive, aerospace, and defense industries, however, traditional fusion-based deposition methods can lead to solidification cracking, void formation, and loss of strength in the heat affected zone. Solid state methods, such as additive friction stir deposition (AFSD), mitigate these challenges by depositing material at temperatures below the melting point. In this work, a solid state volumetric repair was performed using AFSD of aluminum alloy 6061-T6 to fill grooves machined into the surface of a plate of 6061-T651. The groove-filling process is relevant to replacement of cracked or corroded material after removal by localized grinding. Three groove geometries were evaluated by means of metallographic inspection, tensile testing, and fatigue testing. For the process conditions and groove geometries used in this study, effective repairs were achieved to a depth of $3.1-3.5 \mathrm{~mm}$. Below that depth, the interface between the substrate and AFSD filler exhibited poor bonding associated with insufficient shear deformation. The mechanical properties of the filler alloy, the depth of the heat affected zone, and areas for further optimization are discussed within the context of precipitation hardened aluminum alloys.

\section{Full Text}

Due to technical limitations, full-text HTML conversion of this manuscript could not be completed. However, the manuscript can be downloaded and accessed as a PDF.

\section{Figures}

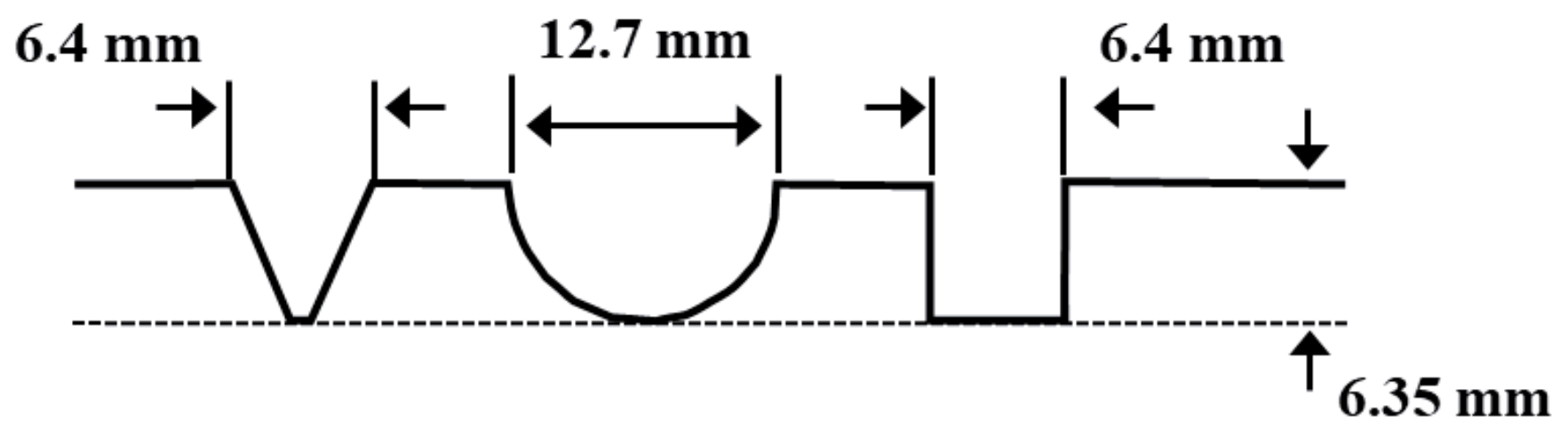

Figure 1

Geometry of the grooves machined into the substrate plates to simulate material removal during a repair operation 


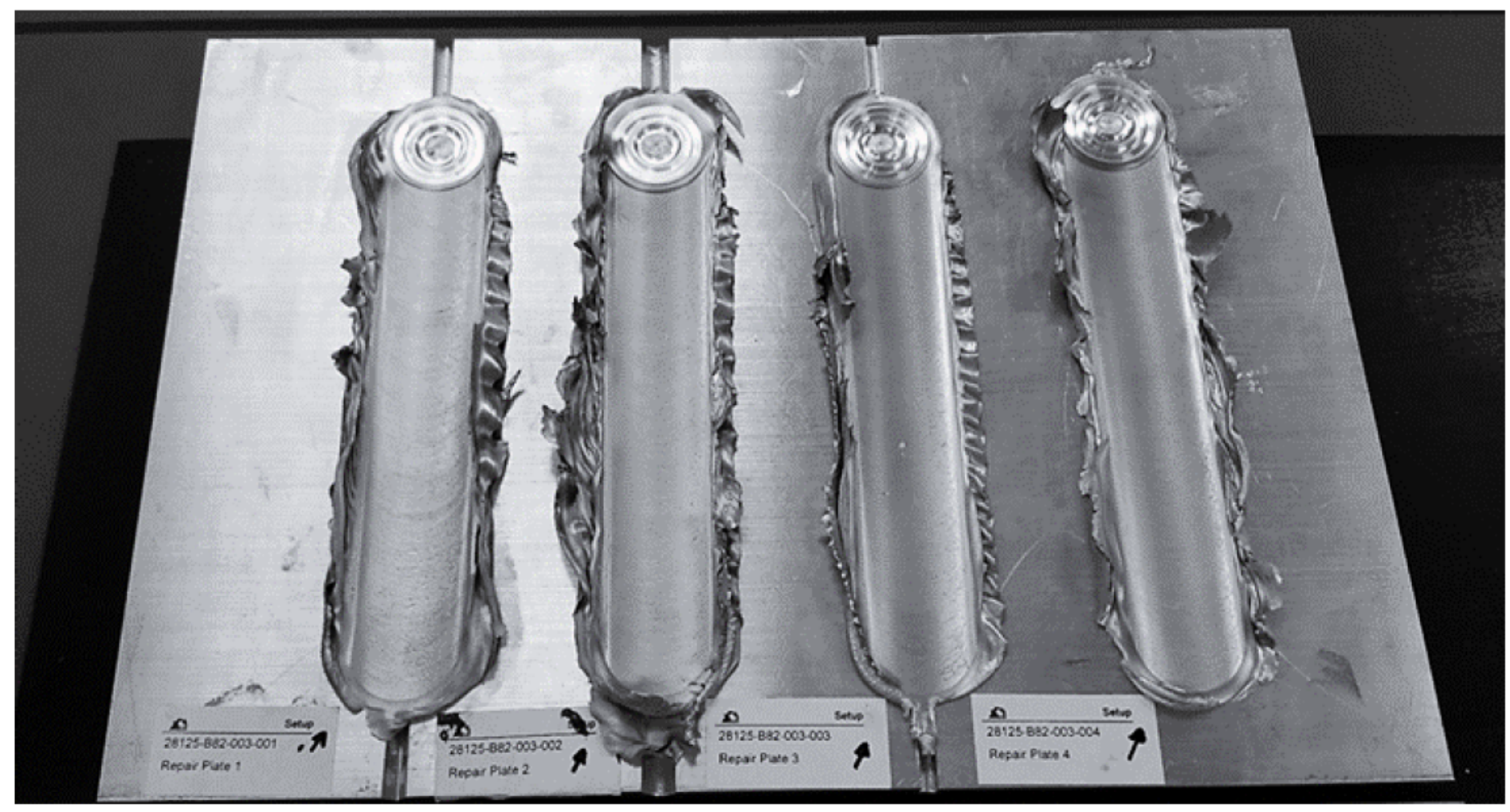

Figure 2

AFSD build on the $6061-T 651$ plate $(450 \mathrm{~mm}$ x $305 \mathrm{~mm})$. The depositions cover, from left, V-grooves, Rgrooves, S-grooves, and an additional section not used in this investigation 
a.
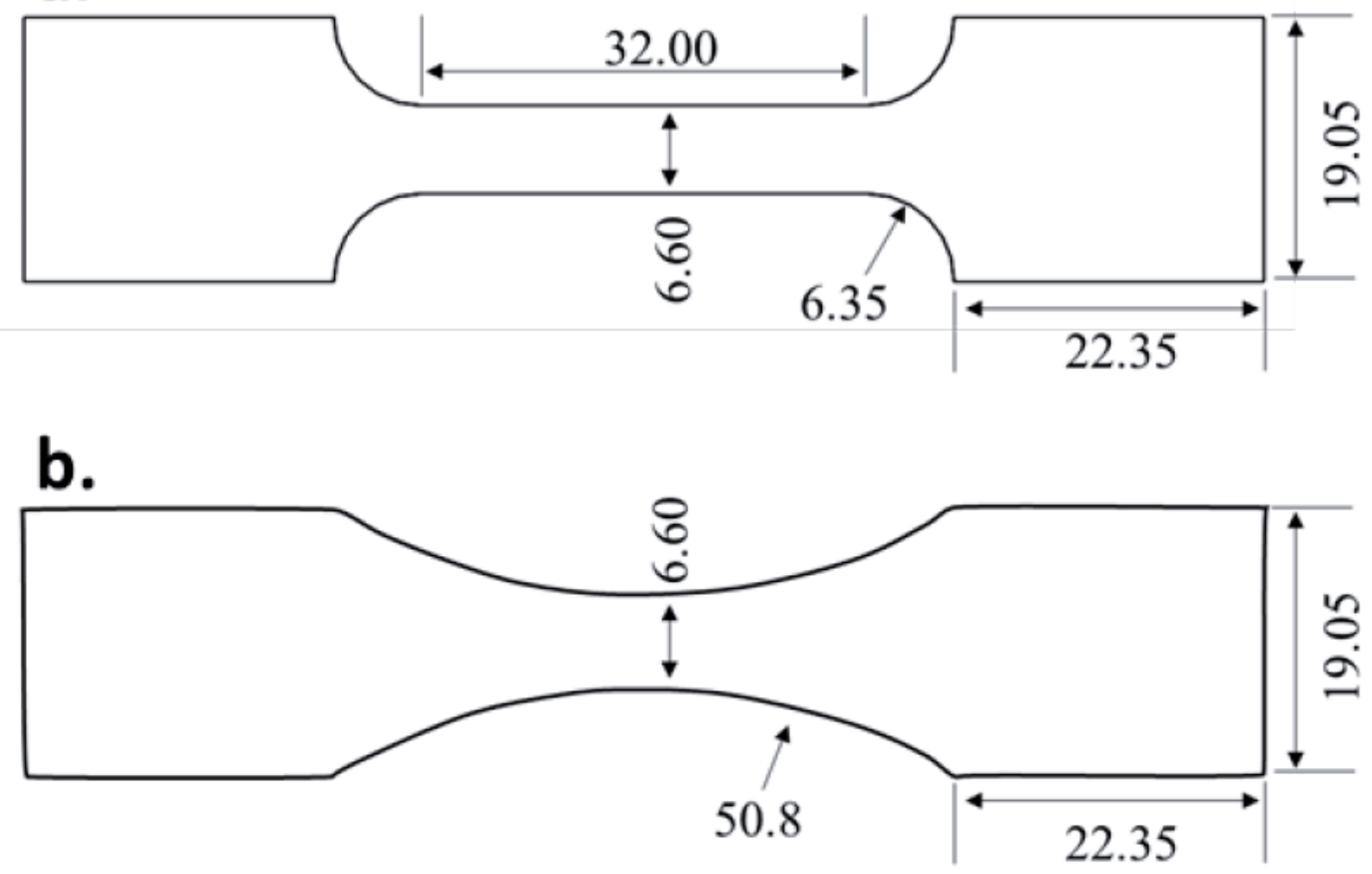

Figure 3

Showing the geometry of the mechanical test samples: a) tensile, b) fatigue. All samples were $6.35 \mathrm{~mm}$ thick, and all dimensions shown are in millimeters
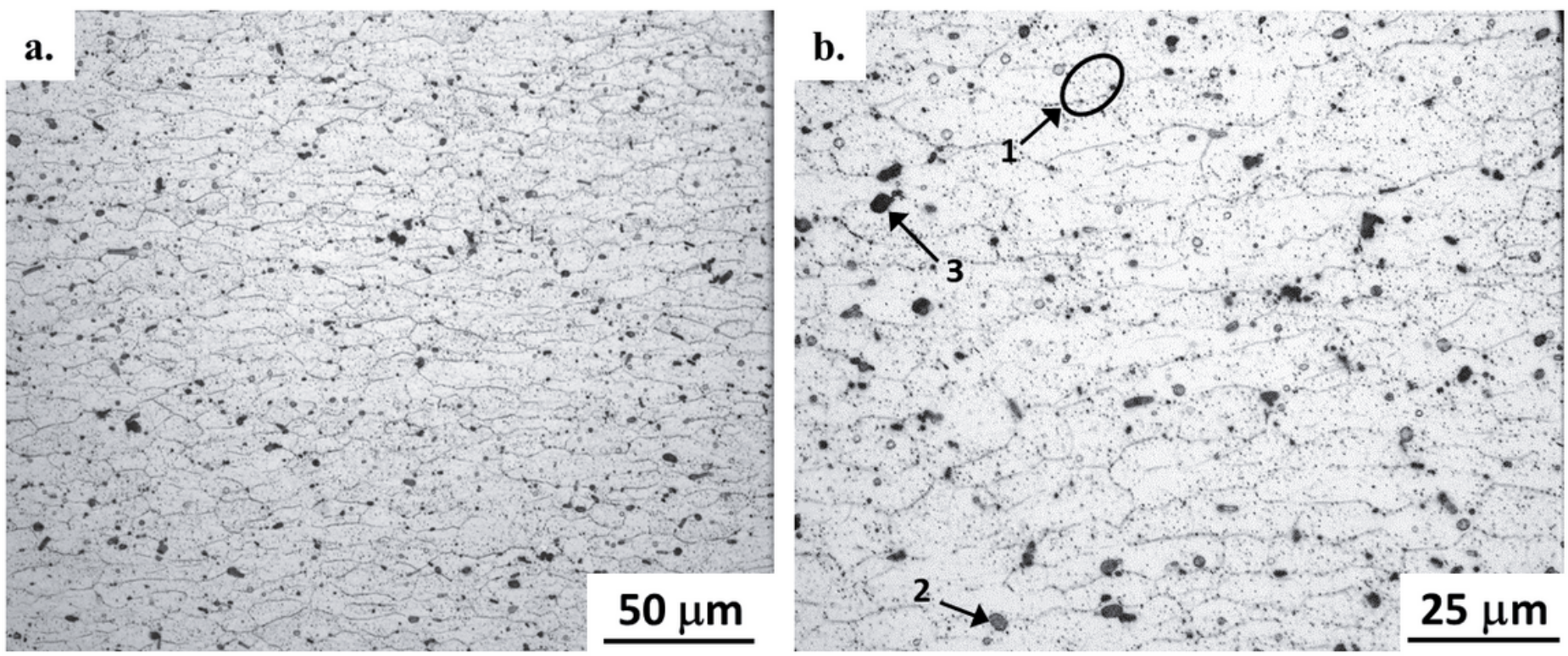
Figure 4

Light optical microscopy images showing the as-received microstructure in the 6061-T651 substrate. The annotations in (b) indicate examples of: 1) excess Mg2Si inclusions, 2) Fe-containing intermetallic inclusions, and 3) etch pits
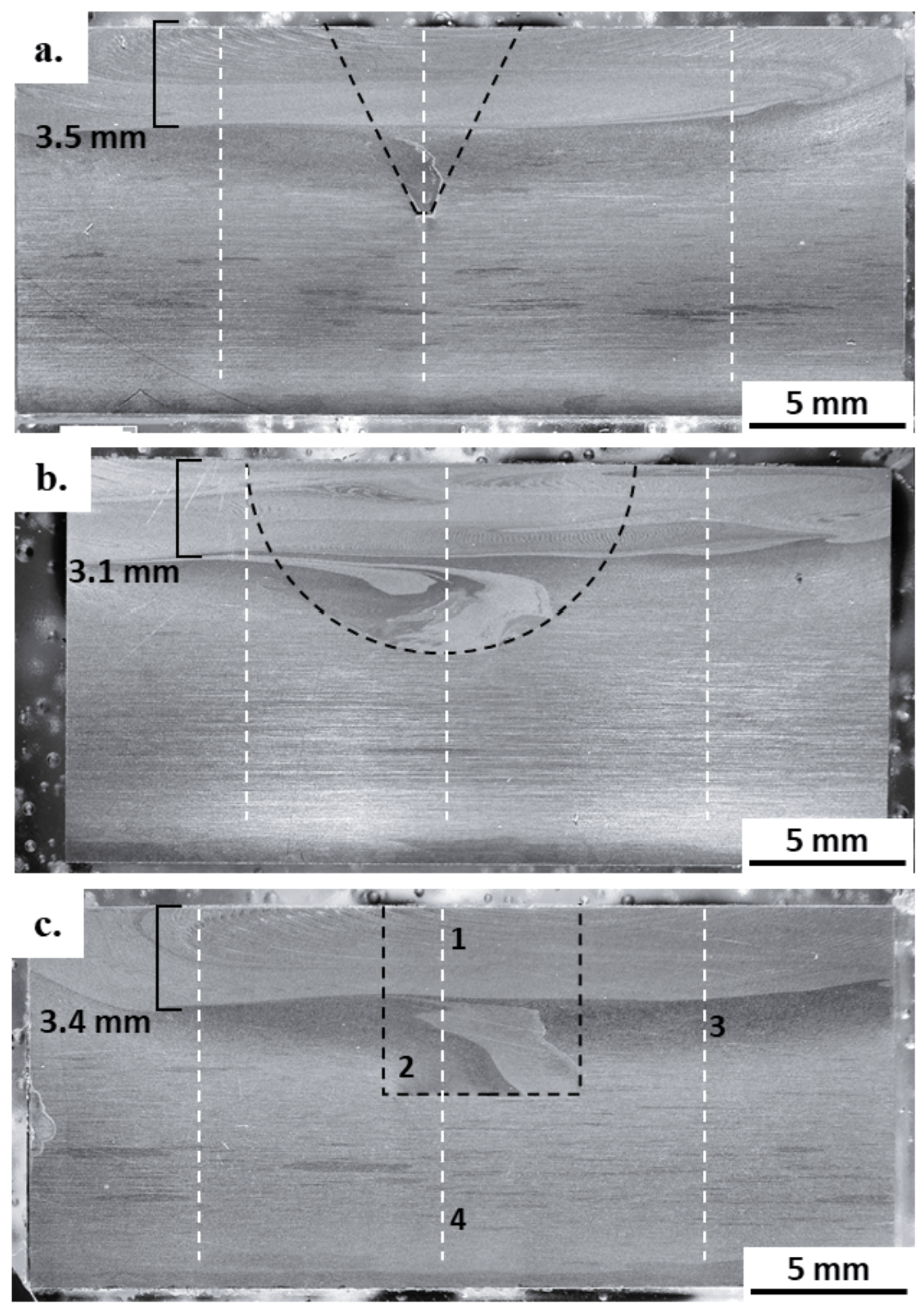

Figure 5 
Light optical microscopy images of cross-sections from the three AFSD-filled grooves in the 6061-T651 plate: a) V-groove, b) R-groove, and c) S-groove. The microstructures shown in Fig. 6 were observed at the locations indicated in (c): $1-\mathrm{SZ}, 2-\mathrm{TMAZ}, 3-\mathrm{HAZ}$, and $4-\mathrm{BM}$. The vertical lines indicate the locations of the hardness profiles in Fig. 8
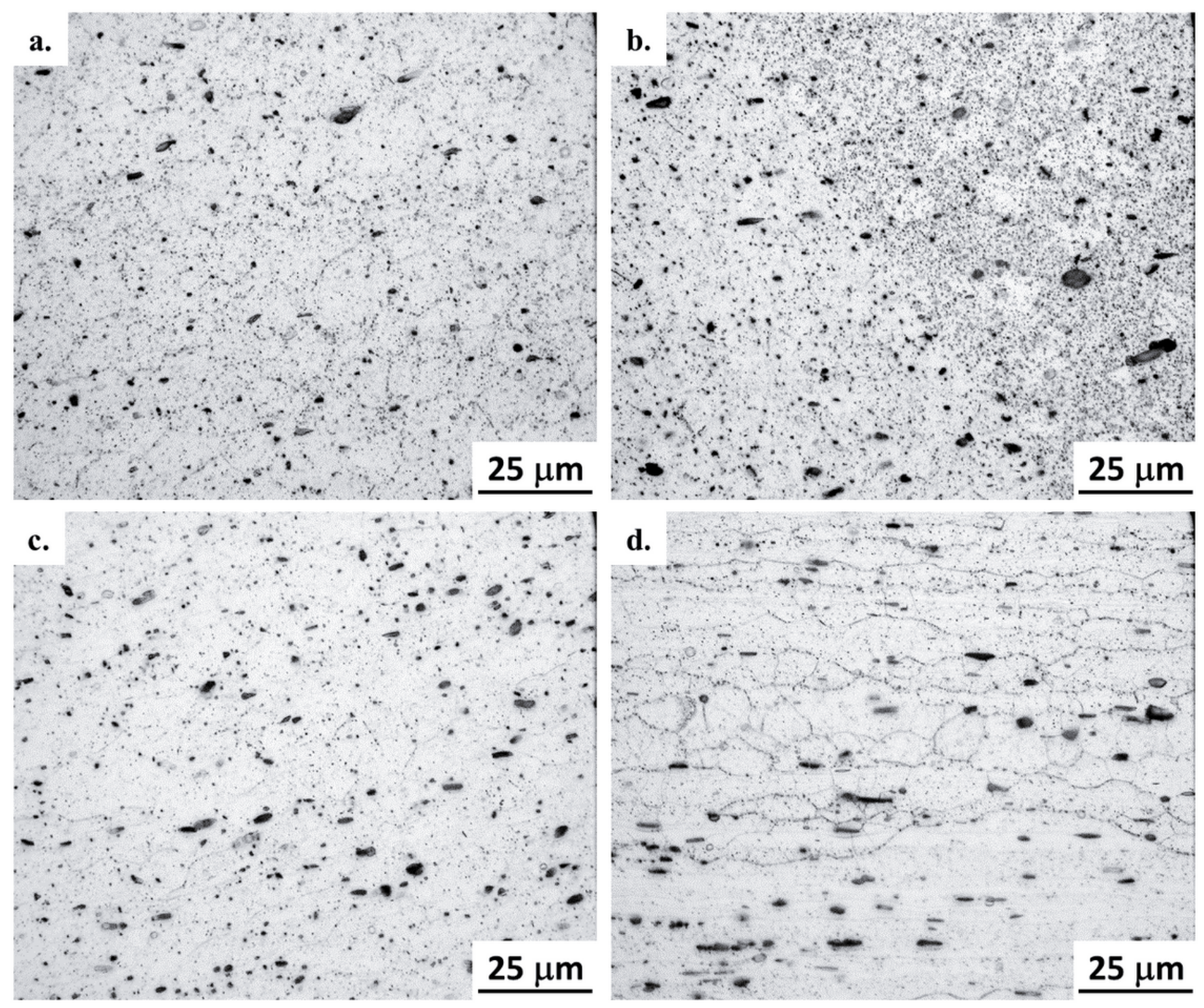

Figure 6

Light optical micrographs of the microstructures observed at locations 1 - 4 in Fig. 5c: a) stir zone (SZ) at location $1, b)$ thermomechanical affected zone (TMAZ) at location 2, c) heat affected zone (HAZ) at location 3 , and d) base metal (BM) at location 4 

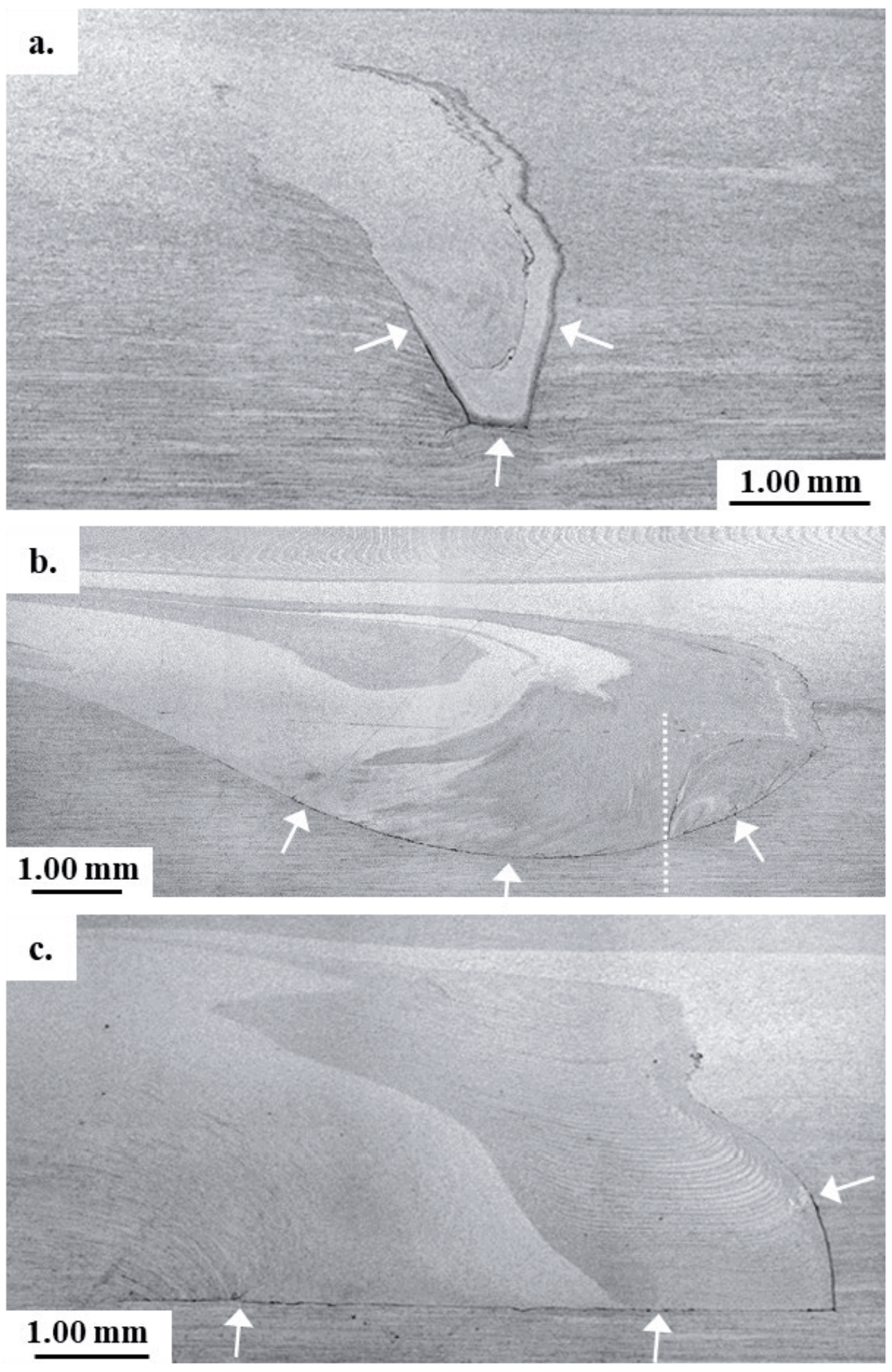

\section{Figure 7}

Light optical microscopy images of cross-sections from the three AFSD-filled grooves in the 6061-T651 substrate: a) V-groove, b) R-groove, and c) S-groove. The dashed line in (b) indicates the approximate position of the fracture surfaces in Figs. 12a and 12b 

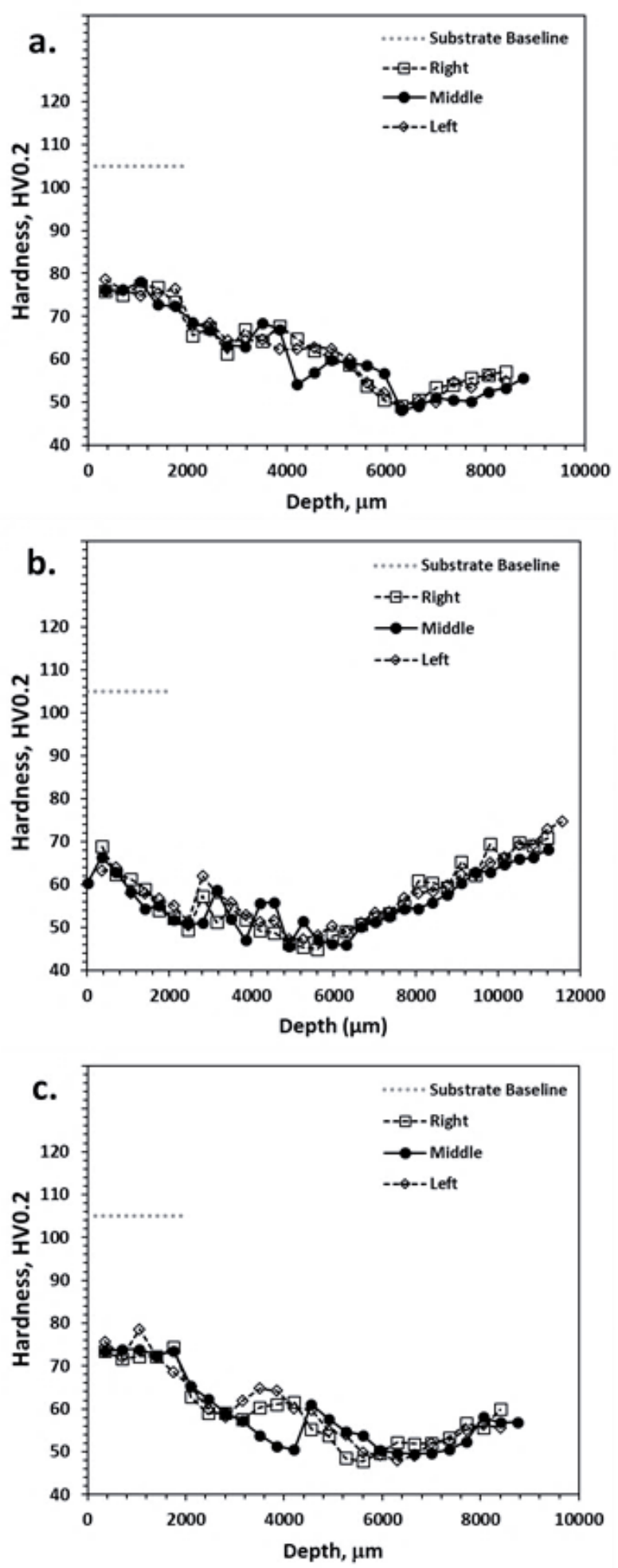

\section{Figure 8}

Vickers hardness depth profiles for the AFSD-filled grooves: a) V-groove, b) R-groove, and c) S-groove. Note the different scale for the $x$-axis in (b) 

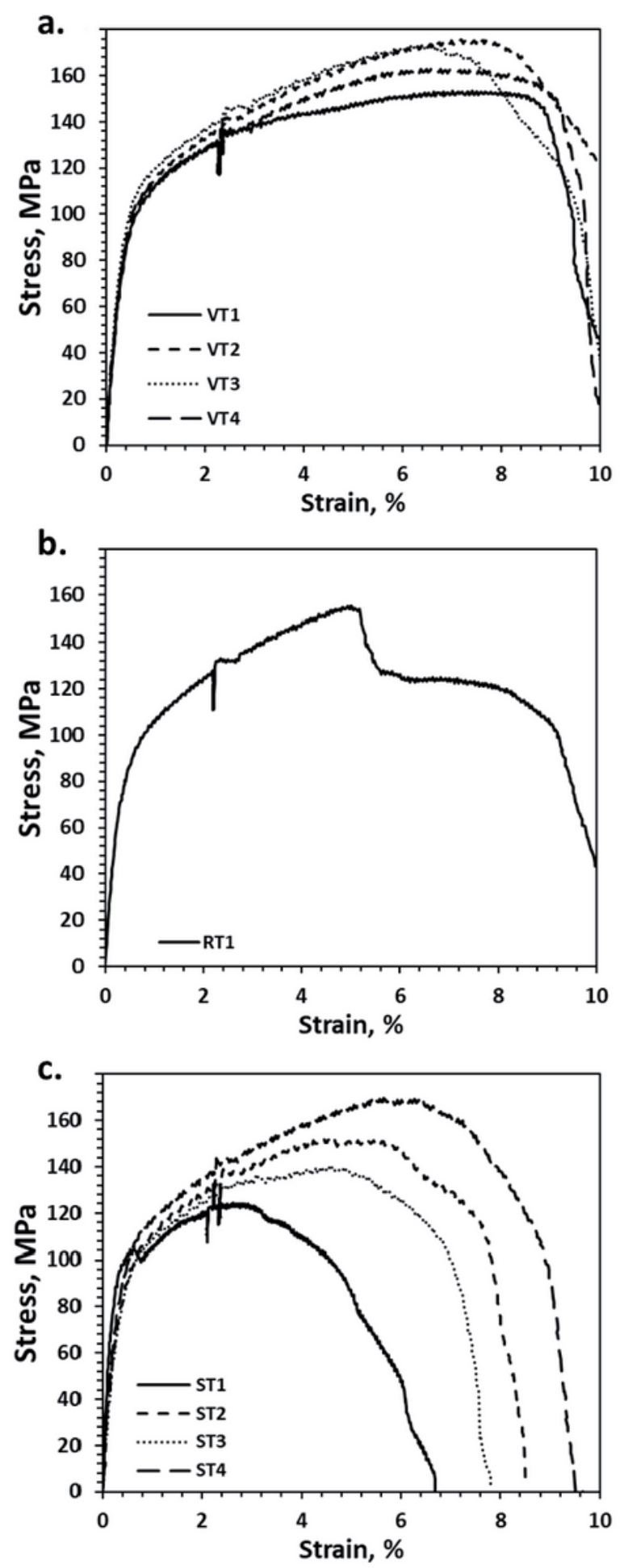

Figure 9

Stress - strain curves from tensile testing of the different groove geometries: a) V-groove, b) R-groove, and c) S-groove 

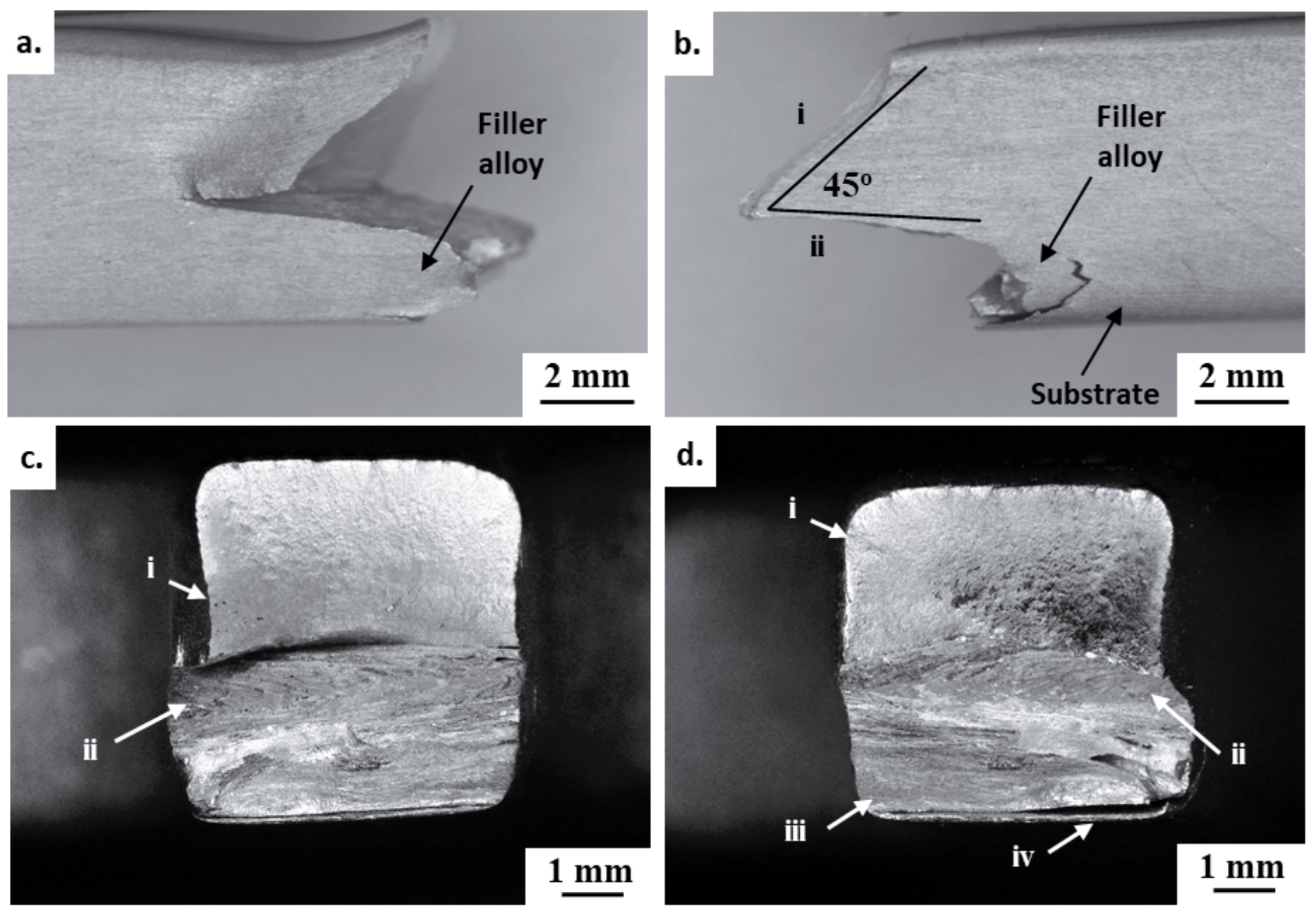

$1 \mathbf{~ m m}$

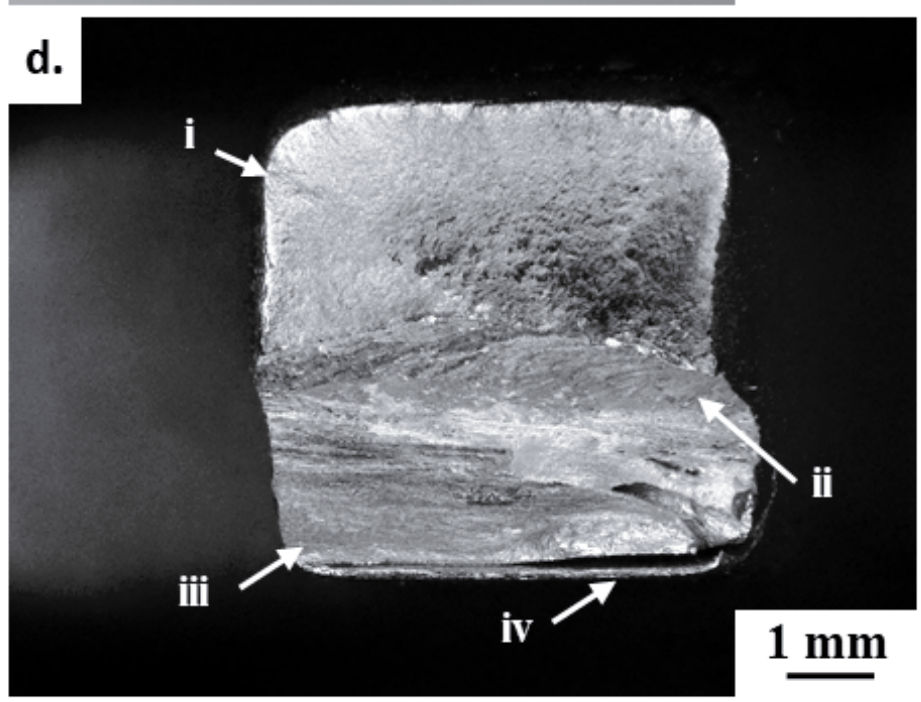

\section{Figure 10}

Light optical microscope images of: $(a, b)$ the profile of the fracture from tensile sample RT1, and $(c, d)$ the corresponding fracture surfaces from the same sample. The labelled features are: i) ductile shear lip, ii) weakly-bonded interface at the base of the SZ, iii) unbonded surface from near the base of the groove, and iv) unbonded filler-substrate interface 

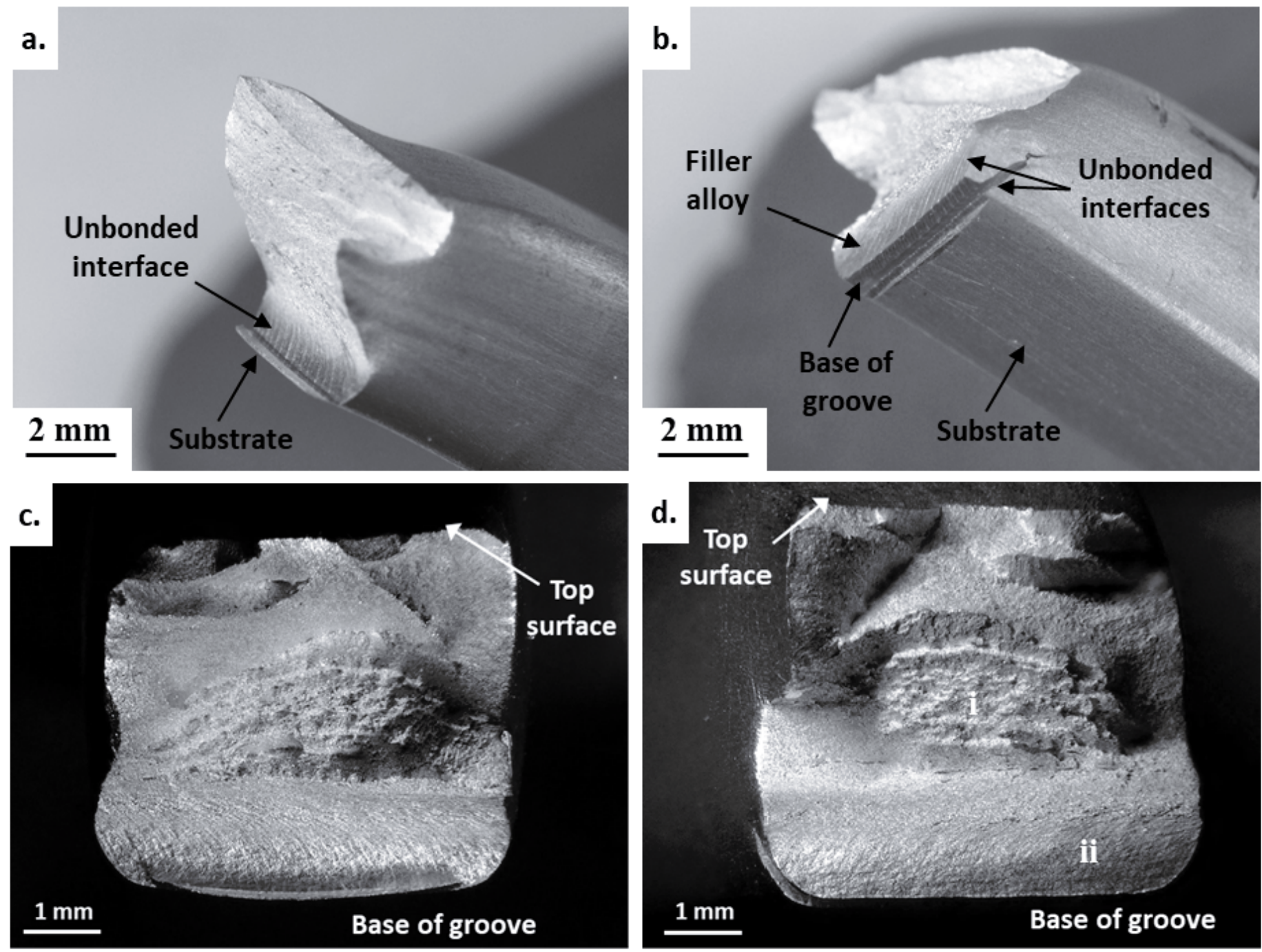

\section{Figure 11}

Light optical microscope images of: $(a, b)$ the profile of the fracture from tensile sample VT2, and $(c, d)$ the corresponding fracture surfaces from the same sample. Scanning electron micrographs from the labelled locations $i$ and ii in (d) are shown in Fig. 12 

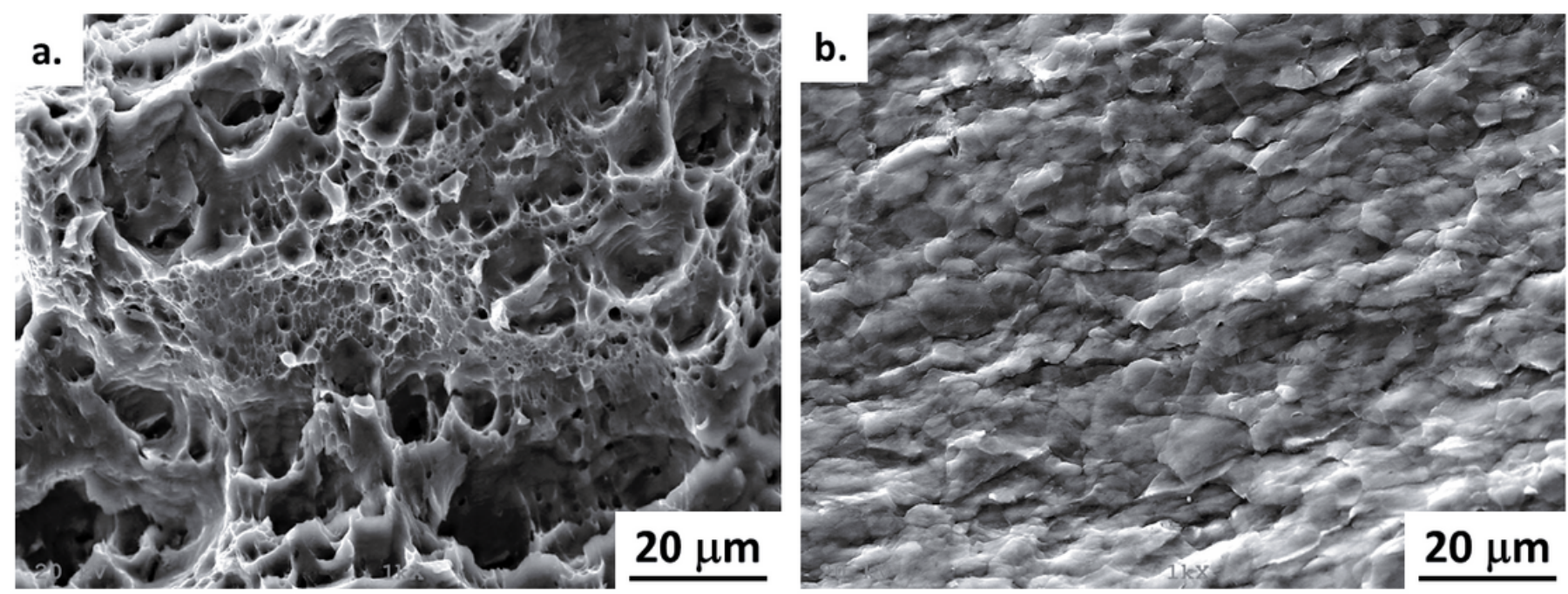

Figure 12

Scanning electron micrographs from the labelled locations in Fig. 11d: a) location 'i' from the ductile SZ, and b) location 'ii' from the unbonded base of the groove
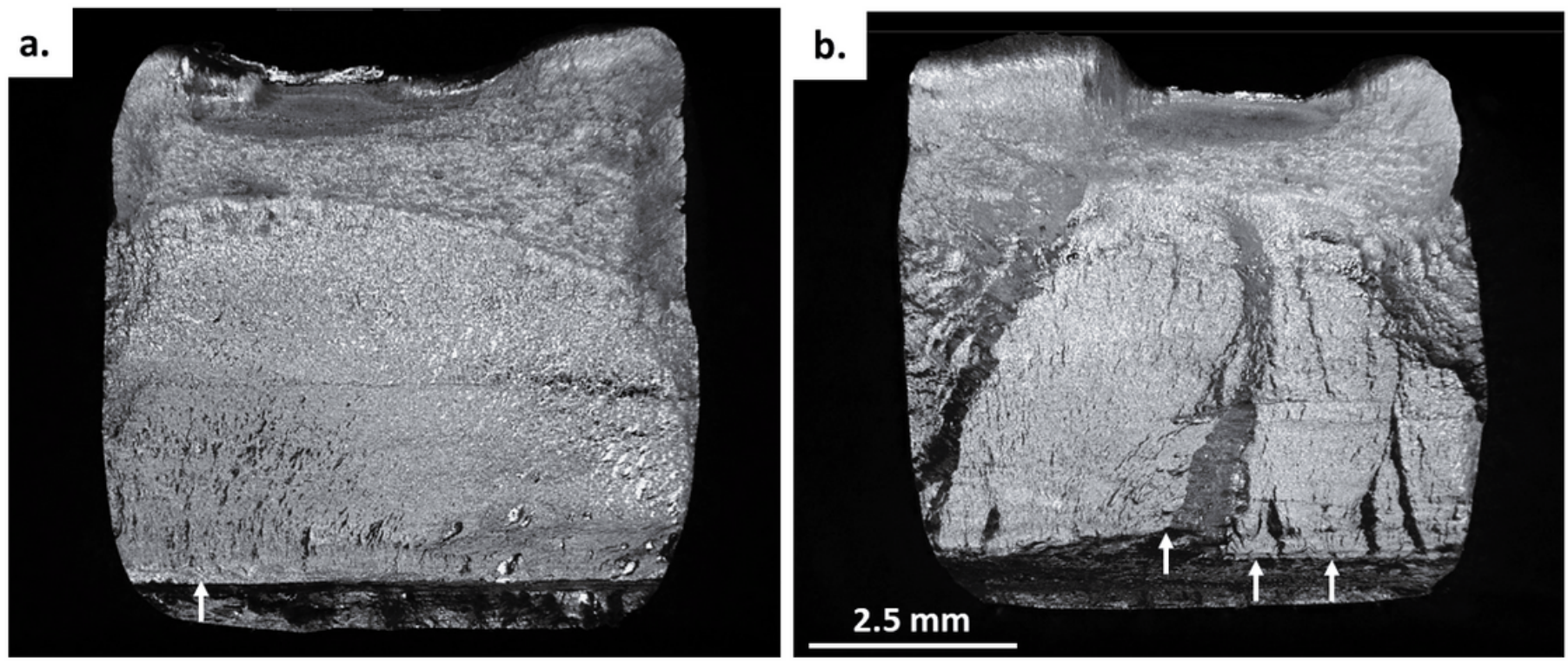

Figure 13

Fracture surfaces from fatigue samples a) RF5, b) RF1. The scalebar in (b) also applies to (a) 